\title{
Effectiveness of Post-injection Grouting in Controlling Leakage: A Case Study
}

\section{Krishna Kanta Panthi}

\begin{abstract}
In many occasions severe water leakage problems are faced in shotcrete lined or unlined water tunnels that not only reduce stability of the rock mass but also result in loss of valuable water in conveying tunnel systems. Such leakage causes safety risks and increases the potential for huge economic loss to the hydropower projects. On the other hand, use of full concrete lining as final support increases the construction cost and time considerably. The best way to reduce leakage control and construction costs and time is the use of pre-injection grouting in the headrace tunnels. This paper discusses the role that post-injection grouting has played for controlling leakage through shotcrete lined/unlined low pressure headrace tunnel of the $60 \mathrm{MW}$ Khimti I Hydropower Project in Nepal.
\end{abstract}

Key words: Post-injection grouting, tunneling in Himalaya, controlling leakages in tunnels, Khimti, Nepal

\section{Introduction}

The rock itself is a significant barrier against groundwater movement if it has low porosity and is un-weathered. The existence of discontinuities in rock mass, however, increases permeability and this permeability may vary widely. In the Himalayas, due to active tectonic activity rock mass is more fractured, faulted, sheared and weathered. As a result, the majority of tunnels excavated in this region face severe tunnelling challenges. The selection of right types of tunnelling technique based on sufficiently accurate engineering geological investigation at planning is, therefore, crucial for successful completion of tunnelling projects. Such approach helps to reduce uncertainty and risk associated to delay in completion and cost overruns (Panthi 2006, Panthi 2009). To cope with instability during tunnel excavation considerable quantity of preliminary rock support has to be installed. In addition to preliminary support, full concrete lining after completion of excavation is a kind of tradition in the Himalaya. Thus, tunneling through Himalayan rock mass is considered more expensive, time consuming and in some cases economically unattractive for hydropower schemes.

The only way to solve this problem is to include preliminary tunnel rock support installed during excavation as a part of permanent support, and to use pre-injection grouting technique as a control measure for water leakage from water conveying tunnels. This concept was used in the headrace tunnel of Khimti I Hydropower Project (6o MW) in Nepal. Among the most important aspects of this unlined/shotcrete lined headrace tunnel concept was control of water leakage while in operation at full hydrostatic pressure. In case of the Khimti Project, the contractual leakage limit was set to 150 liters per second through $7.9 \mathrm{~km}$ long headrace tunnel, which gives specific leakage of 1.13 liters per minute per meter headrace tunnel (CCC 2002).
To bring water leakage through the headrace tunnel to the specified limit of $150 \mathrm{l} / \mathrm{s}$, both pre-injection and post-injection grouting techniques were used in this project. This paper mainly discusses the effectiveness and uncertainty related to post-injection grouting. In addition, the results of post-injection grouting are briefly compared with pre-injection grouting results.

\section{The Khimti Project}

The Khimti I Hydropower Project is located about 100 kilometers east of Kathmandu, the capital of Nepal (Figure 1). The owner of this project is Himal Power Limited (HPL) and Khimti is among the first privately owned hydropower projects in the country. The Civil Construction Consortium (CCC), a joint venture between Himal Hydro, Nepal and Statkraft AS, Norway, undertook construction work on a turnkey basis in 1996. Construction work was completed in the summer 2001 after a one year defect liability period. The Project has an installed capacity of $60 \mathrm{MW}$ and generates approximately 350 GWh electrical energy annually. To generate this energy, the Project utilizes water from very steep Khimti River, which has an average gradient of about $7 \%$. Khimti I is a high head scheme with a gross head of 684 meters and design discharge amounting to $10.75 \mathrm{~m}^{3} / \mathrm{s}$. The total waterway length of the Project (Figure 2) is slightly more than 10 kilometers (HPL 2000).

The headrace tunnel, which is the main focus of this paper, is a low pressurized tunnel with maximum and minimum static water head of 1.1 and 4 bars at its upstream and downstream end, respectively (Figure 3). The headrace tunnel is approximately 7.9 kilometers long with inverted D-shape and 14 square meters cross-section. Except for the first 418 meters at the downstream end with fully reinforced concrete lining, the tunnel is neither lined nor shotcrete supported. The main type of rock support used consists of pre- and post-injection grouting, steel fiber shotcrete, systematic rock bolting and spilling (Panthi and Nilsen 2005, 2010). 


\section{Project Geology}

The Project lies in the crystalline Tamakoshi gneiss complex of the lesser Himalaya and the area is bounded or surrounded by a major fault system in the Himalaya called 'Main Central Thrust' (MCT) (Figure 1). The rocks in the project area are mainly augen gneiss with the intercalation of bands of chlorite and talcose mica schist. This intercalation was observed frequently at an interval of five to 10 meters at the downstream section of headrace tunnel, whereas at upstream stretch the interval is longer and rocks are more fractured and

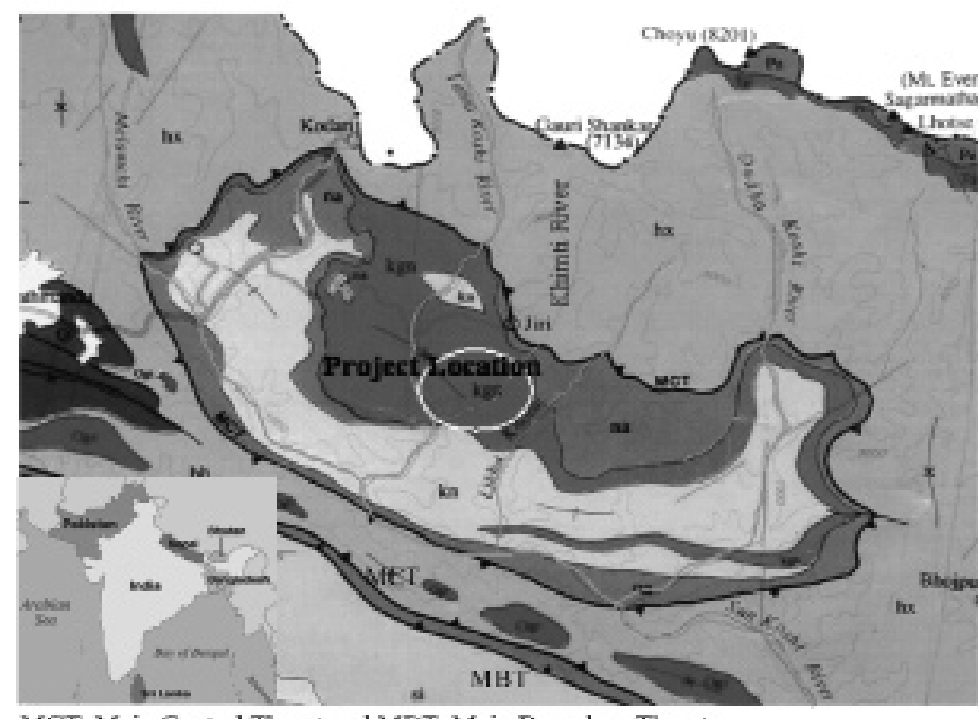

MCT: Main Central Thrust and MBT: Main Boundary Thrust quality along the tunnel during excavation. After tunnelling of about $2.5 \mathrm{~km}$ headrace tunnel from different construction adits, the contractor realized that the estimated rock mass quality presented during contract negotiations were not correct and that he also needed special measures to limit water leakage through the waterway system specified in the contract. In fact, at the end of completion, only approximately $7 \%$ of the headrace tunnel was found to pass through fair to good quality rock mass, and remaining 95\% headrace tunnel passed through poor, very poor, to extremely poor rock class (Panthi 2006, Panthi and Nilsen 2007).

With respect to discontinuity patterns, three sets of joints with occasional random joints were mostly recorded along the headrace tunnel alignment. The general strikes of main foliation joints (Jf) were found varying from N15o to 60oE. This is not very favorable relative to the headrace tunnel alignment, which also is oriented in north-
Fig 1. Project location and Geological Map of the Projcet.

open jointed. The foliation planes are generally striking towards northeast-southwest direction and dipping towards the northwest. Since the project area is bounded with the MCT, the rocks along headrace tunnel are jointed, sheared, deeply weathered and deformed. The area is also influenced by several minor faults and weakness zones represented by very weak sheared schist and crushed zones (Panthi 2006).

\section{Rock Mass Conditions}

The planning phase investigation and predictions of rock mass conditions in Khimti I Project were poor and challenging for the turnkey contractor while planning the tunneling works. The Design Basis Memorandum (HPL 1995a), the main guideline for the turnkey contractor in planning and detailed design of the project, states that most of the tunnel length will be in sound rock. Exceptions were described to be the construction adits, the initial section close to intake and at the downstream end of the headrace tunnel (Figure 2) where the tunnel was predicted to pass through weathered rocks where lining might be needed.

The contractor believed that the rock mass along headrace tunnel would be homogeneous and of good quality and no cost measures for water leakage control were considered during turnkey contract negotiations. However, huge deviations were found on the rock mass east-southwest direction (Figure 2). The foliation joints are mostly dipping towards northwest with a varying dip angle of 50 to 60 degrees at the southern part of the tunnel (Adit 4 area). This trend changes gradually making the dip angle more flat with almost 25 degrees at its northern part. The joint set number one ( $\left.\mathrm{J}_{1}\right)$ is oriented with almost the same strike direction as the foliation joints and is very close to parallel to the tunnel alignment, but is dipping opposite to the foliation joints (dip angle 50 to 75 degrees towards southeast). Joint set number two (J2) is oriented in northwest-southeast direction with very steep dip angle (70 to 85 degrees) towards southwest.

With respect to joint filling and alteration, most of the discontinuities at the southern section (downstream from Adit 3) of the headrace tunnel are filled with clay and bands of chlorite and talcose mica schist, and are characterized as impermeable with respect to water leakage. Nevertheless, the discontinuities present at the northern section of the headrace tunnel are either open or filled with coarse grained permeable silt materials. In this northern section several open joints with aperture of up to $10 \mathrm{~cm}$ were observed. Moreover, the degree of weathering along the tunnel alignment varies greatly and classifies as medium to highly weathered according to ISRM (1978). In some sections the degree of weathering was so deep that decomposed organic soil was 
found in the tunnel. Especially the tunnel section 500 meters downstream from Adit 2 (Figure 2) was very heavily weathered (CCC 2002). The valley side slope in this stretch of the tunnel is flatter (about 25 degrees) and the rock cover is approximately 100 meters.

Since discontinuities upstream from Adit 3 are either open or filled with permeable materials, the possibilities of considerable leakage during operation of the

\begin{tabular}{|l|c|}
\hline Headrace Tunnel Location & Leakage Q (1/s) \\
\hline Total Out leakage Measured & $\mathbf{7 0 0}$ \\
\hline From Adit 1 Plug Area & 2.6 \\
\hline From Adit 2 Plug Area & 200 \\
\hline From Adit 3 Plug Area & 0.4 \\
\hline From Adit 4 Temporary Plug & 1.8 \\
\hline From Remaining Headrace & 495.2 \\
\hline
\end{tabular}
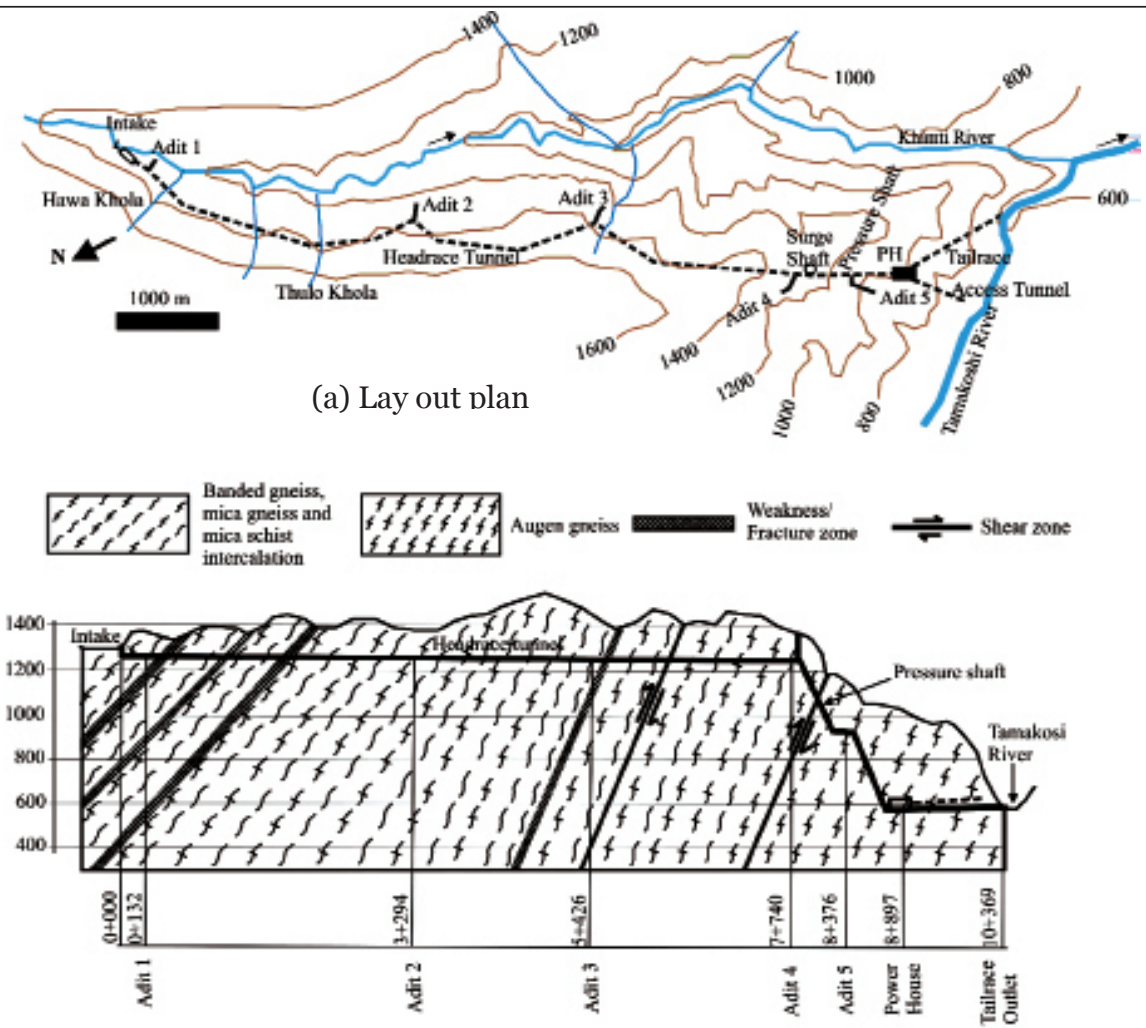

(b) Longitudinal profile with geology

Table 1.Water Leakage After Test Water Filling

known that post-injection grouting is not as effective as pre-injection in water leakage control; nonetheless, the contractor decided to go for postinjection grouting due to a very tight construction schedule.

To be able to concentrate post-injection grouting operation only to the required sections of headrace tunnel as indicated in Figure 3, however, it was necessary to identify the areas where maximum leakage could be expected. To verify this, early test water filling was performed in the headrace tunnel. Since the construction works at the pressure shaft and powerhouse were still not completed, a temporary plug was built at the downstream end of the headrace tunnel at chainage 7505 meters, the end of the concrete lining section located $235 \mathrm{~m}$ upstream from the Adit 4 junction. Test water filling carried out in January 2000 indicated considerable leakage from the tunnel (Table 1).

As expected, the leakage was insignificant from Adit 3 and Adit 4, which gave indication that the pre-injection grouting was effective. Leakage only

Fig. 2. Project topography \& profile iwth Geological Description of water ways

headrace tunnel was most likely. After tunneling almost $2.5 \mathrm{~km}$ of the headrace tunnel from different adits, the contractor realized this problem and had to change the tunnel construction strategy; he incorporated a detail plan for pre-injection grouting for the remaining tunfrom Adit 2, however, was recorded to approximately $200 \mathrm{l} / \mathrm{s}$, indicating that unacceptable leakage was occurring from the headrace tunnel in the area of Adit 2. Note that approximately $1.2 \mathrm{~km}$ tunnelling was carried out nel stretch. However, there were only two alternatives left for water leakage control in the section of headrace tunnel where excavation was already completed: full concrete lining, or post-injection grouting.

\section{Early Water Filling}

Both the orientation and open character of the joints gave clear indication that either full concrete lining or postinjection grouting needed to be carried out at the headrace tunnel stretch where no preinjection grouting was carried out (Figure 3 ). It is well

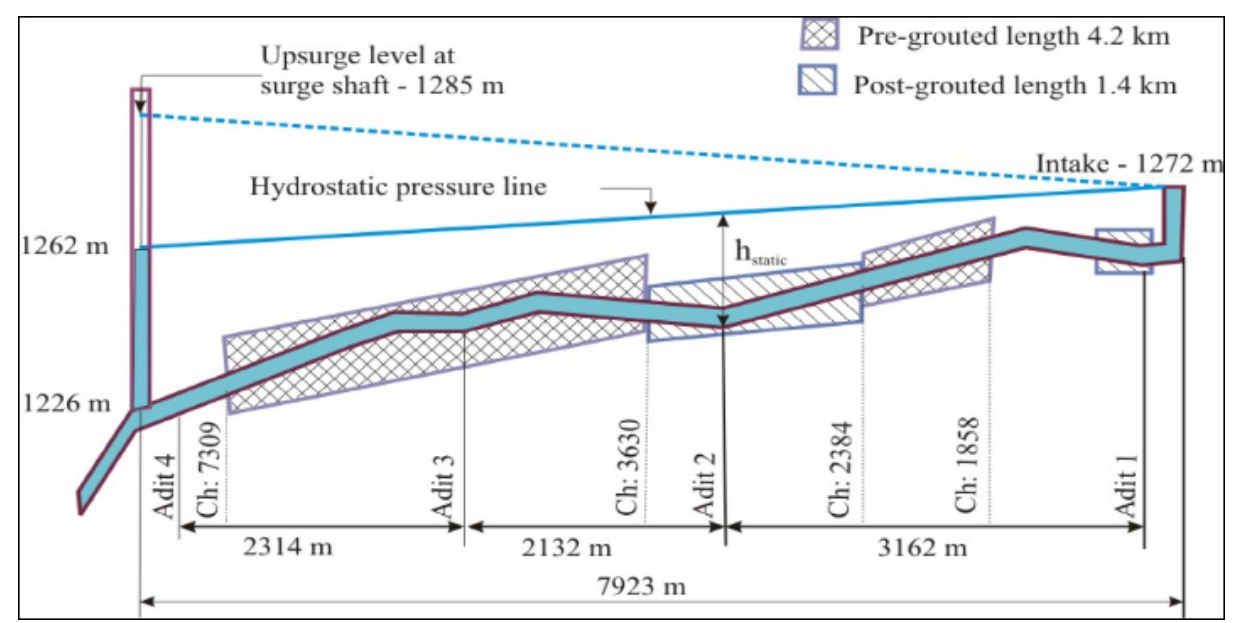

Figure 3. Khimti Headrace Tunnel Profile Showing Hydrostatic Pressure Line During Operation and Areas with Pre-Injection and Post-Injection Grouting (Panthi 2006, Panthi and Nilsen 2010) 
from Adit 2 prior to the pre-injection grouting strategy adopted.

\section{Post-Injection Grouting}

Based on the test water filling results and review of the headrace tunnel geological log, a comprehensive plan was made for implementing post-injection grouting. As shown in Figure 3, the main focus during grouting was given on the ungrouted $910 \mathrm{~m}$ upstream and the 330m downstream stretch of the headrace tunnel from Adit 2 (chainage 2385 to 2965). At this tunnel stretch the joints were open and the rock mass fractured. In addition, some length of the headrace tunnel near Adit 1 (64m upstream and 104m downstream from the Adit 1 junction) where it was suspected water leakage during test water filling was also post-injection grouted. Ordinary cement was used for the grouting mainly due to two reasons; firstly, to reduce cost, since micro cement is approximately 5 times more expensive than that of ordinary cement, and secondly, ordinary cement was considered enough to seal open joints that existed along the headrace tunnel from Adit 2. The maximum grout pressure limit was fixed at four bars for post-injection grouting with typical injection grouting pattern as shown in Figure 4.

Grout holes with alternating length of 12 and six meters respectively, were used for systematic post-injection grouting. The holes were drilled at an angle 45 degrees relatively to the tunnel axis. Two types of water cement ratios were utilized; a water cement ratio of 1.5 was used for post-injection grouting through a primary round of seven nos. 12 meter long holes drilled at every six meters spacing longitudinally and, after completing injection grouting through primary holes, secondary grouting was carried out through a secondary round of five nos. six meter long holes drilled again with six meters spacing between primary rounds. To achieve the desired pressure of four bars, the water cement ratio was reduced to one while grouting through secondary holes.

\section{Grout Consumption}

\section{$12 \mathrm{~m}$ long primary} holes@6m spacing

\section{$6 \mathrm{~m}$ long secondary}

holes@6m spacing
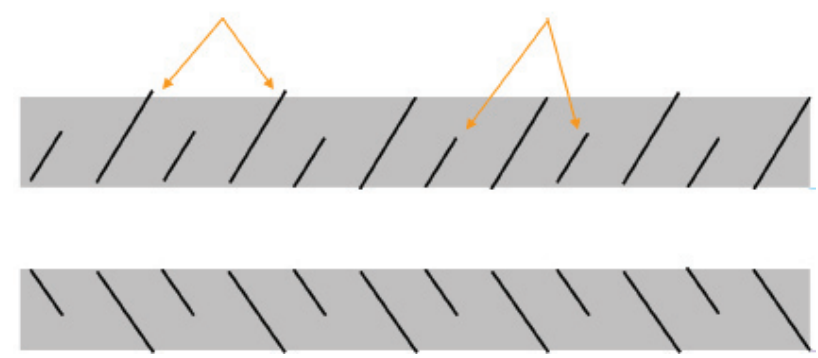

Figure 4. Used Post-Injection Grouting Pattern

Altogether 1408 meters of headrace tunnel were covered with post-injection grouting (Figure 3) and 941 tons of ordinary cement was injected into the rock mass. The total injected quantity of cement for 1240 meters of headrace tunnel from Adit 2 upstream and downstream consisted of 871 tons. This quantity gives a mean specific grout consumption of $702 \mathrm{~kg}$ per meter tunnel. The mean grout take for each hole at this tunnel stretch consisted to approximately $920 \mathrm{~kg}$. In general, the grout take through primary holes was more than 60\% higher than the grout take through secondary holes. There was also some variation in grout take through holes drilled in the valley side, in the hillside and in the crown of the tunnel (Figure 5).

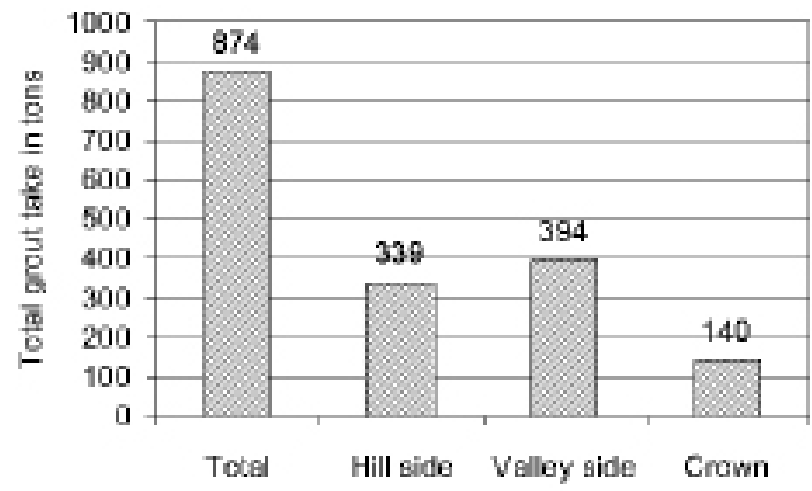

Figure 5. Post-Injection Grout-Take through 1240m Headrace Tunnel at Adit 2

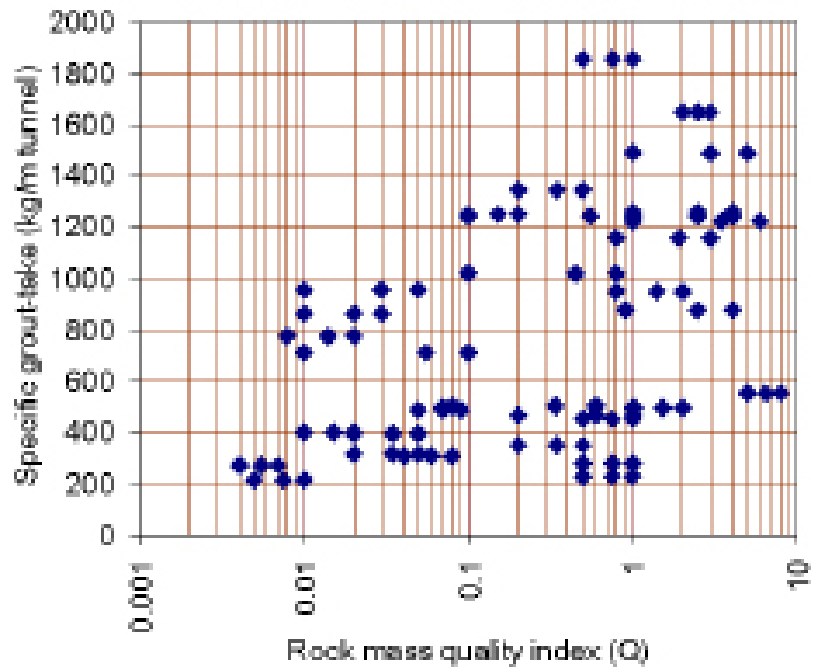

Figure 6. Specific Post-Injection Grout-Take and Q Value

Figure 6 indicates that it is difficult to interlink specific grout take with rock mass quality index Q. Nevertheless, the likelihood of elevated grout-take through rock mass having Q-value between 0.1 and 4 (class III rock mass) was maximum. This is quite logical since the rock mass in this category is typically open jointed or filled with permeable silt material. Very poor rock mass has a likelihood of more clay infilling in the joints, which reduces rock mass permeability and the grout take is lower. Similarly, rock mass with higher Q-value has less frequently occurring joints with reduced interaction between them.

\section{Effectiveness of post-injection grouting}

In general, both pre and post-injection grouting was found to be effective and economical solutions for controlling water leakage from a low pressurized headrace tunnel. Compared to pre-injection, the post-injection grouting was difficult and challenging to carry out. The 


\begin{tabular}{|l|r|r|}
\hline $\begin{array}{l}\text { Descriptions } \\
\text { A. Pre-injection Grouting }\end{array}$ & $\mathrm{M}$ & 4612 \\
\hline Grouted length & $\mathrm{Bars}$ & 3 to 6 \\
\hline Grouting pressure & $\mathrm{Kg}$ & 754,975 \\
\hline Total consumption & $\mathrm{kg} / \mathrm{m}$ tunnel & 163 \\
\hline Specific consumption & $\mathrm{M}$ & 1408 \\
\hline B. Post-injection Grouting & Bars & 4 \\
\hline Grouted Length & $\mathrm{Kg}$ & 941,260 \\
\hline Grouting Pressure & $\mathrm{kg} / \mathrm{m}$ tunnel & 668 \\
\hline Total consumption & & \\
\hline Specific consumption & &
\end{tabular}

Table 2: Grouting Results in Khimiti Headrace Tunnel

tendency of outflow of grout material in the tunnel wall was high, and due to open joints it was often difficult to achieve desired grout pressure of 4 bars. As a result, grout consumption was considerably higher than for pre-injection grouting (Table 2). In addition, the postinjection grouting operation was much more costly.

After the completion of post-injection grouting the water way system of the Khimti I Hydropower Project was water filled. Leakage measurements were carried out in accordance with the performance guarantee in the civil works contract $(\mathrm{KC} 2)$; the result was a leakage of 120 liters per second through 7,923 meter long headrace tunnel. This gives a specific leakage (q) equivalent to 0.91 liters per minute per meter headrace tunnel, which is far below than the contractual leakage limit.

\section{Conclusion}

The systematic post-injection grouting at Khimti headrace tunnel was effective to control water leakage to the contractual limit. The post-injection grouting considerably helped to complete the project within the contractual deadline and also helped reduce project construction cost. The achieved grouting result demonstrates that if carefully planned the systematic post-injection grouting may also be practical and play a significant role in the reduction of water leakage from a low pressurized unlined/shotcrete lined water conveying headrace tunnel, and considerably reduces overall construction time and cost .

The Khimti case also illustrates that grouting operations are not easy tasks, especially post-injection grouting, which is much more costly than pre-injection grouting. Therefore, systematic pre-injection grouting should be used as much as possible. Moreover, to achieve good grouting result at the lowest possible cost, a good understanding of the ground conditions is of great impor- tance. Although there were many uncertainties and risk connected to the post-injection grouting, success was achieved with tremendous savings in cost and time.

Dr. Krishna Kanta Panthi is an Associate Professor in Geological Engineering in the Department of Geology and Mineral Resources Engineering, Norwegian University of Science and Technology (NTNU), Trondheim, Norway. He has completed his Dr. Ing. degree on the 'Analysis of Engineering Uncertainties Related to Tunneling in Himalayan Rock Mass Conditions' in 2006 from NTNU. He completed his M.Sc. in Hydropower Development in 1998 and M.Sc. in Civil Engineering in 1992. He is the author of many scientific papers related to tunneling, rock slope engineering and hydropower. He has over 15 years of experience in design, construction and planning of tunneling and hydropower projects in the Himalaya (Nepal and India).

Corresponding Address: krishna.panthi@ntnu.no

\section{References}

CCC, 2002, Construction Report: Khimti I Hydropower Project, v.1, Kathmandu: Civil Construction Consortium.

HPL, 1995a, Project Definition Report, Khimti I Hydropower Project, Kathmandu: Himal Power Ltd.

HPL, 1995b, Civil Works Contract (KC2), Khimti I Hydropower Project, v.1 (Main Text), Kathmandu: Himal Power Ltd.

HPL, 2000, Final Design Report, Khimti I Hydropower Project, v.1 (Main Text), Kathmandu: Himal Power Ltd.

ISRM, 1978, 'Suggested methods for the quantitative description of discontinuities in rock mass', International Journal of Rock Mechanics (Mining Sciences and Geomechanics Abstracts), 15:319-368.

Panthi, K.K. and B. Nilsen, 2005, 'Significance of grouting for controlling leakage in water tunnels: A case from Nepal', Proceedings of ITA-AITES 2005 World Tunneling Congress and 31st ITA General Assembly, Istanbul, Turkey, pp. 931-937

Panthi, K.K. and B. Nilsen, 2007, 'Predicted versus actual rock mass conditions: A review of four tunnel projects in Nepal Himalaya', Tunneling and Underground Space Technology 22:173-184.

Panthi, K.K. and B. Nilsen, 2010, 'Uncertainty analysis for assessing leakage through water tunnels: A case from Nepal Himalaya', Rock Mechanics and Rock Engineering (DOI 10.1007/s00603-009-0075-8) 43: 629-639.

Panthi, K.K., 2006, Analysis of Engineering Geological Uncertainties Related to Tunneling in Himalayan Rock Mass Conditions, PhD Dissertation, Norwegian University of Science and Technology.

\section{CALENDAR OF EVENTS}

\section{Environment}

25-27 March 2011, 2011 International Conference on Future Environment (ICFEE 2011), Location: Sanya, Hainan, China. http://www.icfee.org/

Drinking Water \& Sanitation

April 2011, The 4th South Asian Conference on Sanitation (SacoSan IV) under the theme of "Sanitation enhances life"
Location: Shri Lanka. http://www.iwmi.cgiar.org/\#

25-28 April 2011, 3rd International SmallWat11 Congress: Wastewater in Small Communities. Location: Seville, Spain. E-mail: info@smallwat.org

Rain Water Harvesting

28 March - 4 April 2011, Worldwide Multi-objective Rainwater Harvesting and Utilization, Location:Taipei, Taiwan. www.ircsa.org 